\title{
Sr-Nd-Pb isotope systems as fingerprinting tools to trace anthropogenic controls on the Weser river system (Germany)
}

FEIFEI DENG ${ }^{1 *}$, STEFFEN HELLMANN ${ }^{2}$, TRISTAN ZIMMERMAN $^{1}$, AND DANIEL PRÖFROCK ${ }^{1}$

${ }^{1}$ Institute of Coastal Research, Helmholtz Center Geesthacht,

Max-Plank Str.1, 21502 Geethacht, Germany

(*correspondence: feifei.deng@hzg.de)

${ }^{2}$ Technical University of Applied Sciences Lübeck, 23562,

Lübeck, Germany (steffen.hellman92@gmail.com)

Human activities, such as agriculture and industrial manufacturing, have supplied contaminants to the river systems, and are changing their biogeochemical propertities and ecosystems. These human-induced impacts have put river systems under great pressure in the recent decade. It has therefore become increasingly important to evaluate the anthropogenic controls and quantitatively assess their relative impacts on the river systems. In this study, we explore the potential of the $\mathrm{Sr}, \mathrm{Nd}$, and $\mathrm{Pb}$ isotope systems as a fingerprinting tool to trace anthropogenic controls on historically heavily contaminated river Weser in Germany.

Sediment samples were collected along the river Weser and its tritutaries, covering areas of agricultural land and industrial sites, and expanding to coastal areas of the North $\mathrm{Sea}$. Isotopic ratios of $\mathrm{Sr}, \mathrm{Nd}$, and $\mathrm{Pb}$ were measured on $\mathrm{MC}$ ICP-MS (Multi-collector-Inductively Coupled Plasma-Mass Spectrometry) with the newly-developed automated prepFAST sample purification method [1]. The $\mathrm{Sr}, \mathrm{Nd}$ and $\mathrm{Pb}$ isotope results reported here are the first such dataset obtained from the sediment of the river Weser. Using mixing models, we demonstrate the great potential of the $\mathrm{Sr}, \mathrm{Nd}$ and $\mathrm{Pb}$ isotope systems as fingerprinting tools to identify the sources of contaminants and to evaluate anthropogenic controls on the load of contaminants in the sediment. Coupled with measurement of elemental compositions in the sediment and the principal component analysis, we further provide an evaluation of the relative contribution of various sources to the load of contaminants in the river Weser. An attempt is also made to quantify the flux of the river to the North Sea, providing an insight into the contribution of the river system to contaminants transported into the coastal zone.

\section{REFRENCES}

[1] Retzmann, Zimmermann, Pröfrock, Prohaska, Irrgeher (2017), Analytical and Bioanalytical Chemistry 409, 54635480 . 